\title{
Viral etiology of community-acquired pneumonia among adolescents and adults with mild or moderate severity and its relation to age and severity
}

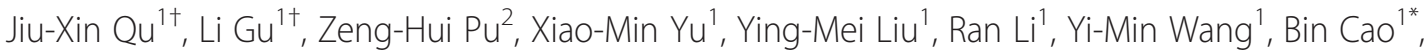 \\ Chen Wang ${ }^{3}$ and For Beijing Network for Adult Community-Acquired Pneumonia (BNACAP)
}

\begin{abstract}
Background: Better knowledge of distribution of respiratory viruses (RVs) in adolescents and adults with community-acquired pneumonia (CAP) is needed.
\end{abstract}

Methods: To investigate the RVs etiology among adolescents and adults with CAP, according to age and pneumonia severity index (PSI), a multi-center, prospective study was conducted from November 2010 to April 2012. Fifteen RVs were tested by polymerase chain reaction (PCR). Bacteria were detected by urinary antigen, conventional culture and PCR.

Results: Mean (SD) age and median (IQR) PSI score of 954 patients enrolled was 45.2 (19.5) years (range 14-94) and 42 (36). RVs were found in 262 patients (27.5\%): influenza virus A (IFV A, 9.9\%) comprised of pandemic H1N1 (6.7\%) and seasonal H3N2 (3.5\%), human rhinovirus (4.3\%), adenovirus (4.2\%), human metapneumovirus (1.8\%), parainfluenza virus 1,3 and $2(1.7 \%, 1.5 \%$ and $1.2 \%)$. Influenza virus $B$, enterovirus, respiratory syncytial virus, human coronavirus and parainfluenza virus 4 were rarely detected $(<1 \%)$. Frequency of IFV A was highest among patients aged between $45-64$ years $(p<0.001)$, while adenovirus among patients aged $14-17$ years $(p<0.001)$, no differences was found in other RVs. The proportion of pandemic H1N1 increased with severity of pneumonia evaluated by PSI (P $<0.05)$.

Conclusions: The proportion of RVs in CAP is higher than previously reported. IFV A pneumonia are usually found in patients older than 45 years, while, adenovirus pneumonia are common in adolescents and young adults. Pandemic $\mathrm{H} 1 \mathrm{~N} 1$ virus is still recognized by PSI as a high-severity pathogen. The findings contribute baseline data on viral CAP study in China.

Keywords: Community-acquired pneumonia, Respiratory viral infection, Pneumonia severity index, Adolescent, Adult, Influenza virus A, Adenovirus, Human rhinovirus

\section{Background}

Community-acquired pneumonia (CAP) remains a common disease associated with significant morbidity and mortality. Mortality varied from $<1 \%$ to $48 \%$ and is associated with advanced age, co-morbid conditions, and CAP severity [1]. Clear etiology is essential for the

\footnotetext{
*Correspondence: cabin_ben@163.com

${ }^{\dagger}$ Equal contributors

'Department of Infectious diseases and Clinical Microbiology, Beijing Chao-Yang Hospital, Capital Medical University, Beijing Institute of Respiratory Medicine, No 8 Gongti Nanlu, ChaoYang District, Beijing 100020, China Full list of author information is available at the end of the article
}

management of CAP patients [2]. Although CAP guidelines acknowledge respiratory viruses (RVs) as a "cause" of adults pneumonia [3], few recommendations are made regarding management, largely due to the short of data regarding prevalence and clinical severity, as most relevant data concern infants and children $[4,5]$. In addition, the emergence of severe acute respiratory syndrome (SARS), avian influenza A (H5N1) virus, and the pandemic influenza A 2009 (pH1N1) virus has emphasized the important role of RVs as causes of CAP [6]. Thus, much better knowledge of the potential role

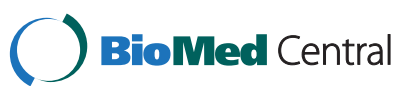

(C) 2015 Qu et al.; licensee BioMed Central. This is an Open Access article distributed under the terms of the Creative Commons Attribution License (http://creativecommons.org/licenses/by/4.0), which permits unrestricted use, distribution, and reproduction in any medium, provided the original work is properly credited. The Creative Commons Public Domain Dedication waiver (http://creativecommons.org/publicdomain/zero/1.0/) applies to the data made available in this article, unless otherwise stated. 
of RVs present in adolescents and adults patients with pneumonia is needed.

In general, compared to conventional viral diagnostic methods (culture, antigen detection, and serological assays), PCR-based methods are $2-5$ times more sensitive to detect RVs [6]. Moreover, use of PCR has augmented detection of viruses that are difficult to identify with conventional methods, including human rhinovirus (HRV), human coronavirus (hCoV), human metapneumovirus (hMPV), and human bocavirus $[7,8]$. Recently, development of several multiplex assays has enabled simultaneous detection of up to 15 different viruses, and use of these tests is becoming standard for identification of respiratory viruses [9-11].

In an attempt to better characterize the viral etiology of CAP in adolescents and adults, a multi-center, prospective surveillance was conducted in 12 general hospitals of Beijing, from November 2010 to April 2012, using a multiplex RT-PCR assay covering all common RVs associated with CAP [12]. We also sought to evaluate age and severity of disease related to different pathogens.

\section{Methods}

\section{Study setting and design}

A prospective study was conducted in 12 general hospitals in Beijing, covering $80 \%$ of 30 million citizens, as described in former report [13]. Between November 2010 and April 2012, patients (aged 14 years or above) who came to the hospitals during daytime and met the inclusion criteria of CAP [3] were enrolled. Patients with HIV infection; neutropenia or chemotherapy; pregnant; known or suspected active tuberculosis, no informed consents or specimens were excluded. The study was approved by institutional review board in Beijing Chao-Yang Hospital (project approval number: 10-KE-49). Written informed consents were provided by all adults and the parents of patients aged less than 18 years.

\section{Patient characteristics and CAP scoring system}

The following data were recorded on enrollment: age, gender, smoking status, comorbid illnesses and antimicrobial treatment prior to enrollment, duration of symptoms prior to visit, clinical symptoms, physical examination, chest X-ray or computed tomography (CT) scan pattern, blood analysis and antimicrobial and antiviral treatment. All surviving patients were followedup by telephone after discharge for four weeks, symptoms and signs were recorded daily. Pneumonia severity index (PSI) score classes were assigned according to the authors' original designations [14]. PSI classes were specified as follows: low risk $=\mathrm{I}-\mathrm{II}$, moderate risk $=\mathrm{III}$, high risk = IV-V.

\section{Microbiological evaluation}

Microbiological examination was performed in throat swab, sputum, urine and blood, at the central laboratory (Clinical Microbiological Laboratory of Beijing ChaoYang Hospital). The etiology was considered definite if one of the following criteria was met: (1) positive urinary antigen for Legionella pneumophila (LP, Binax Now $L$ pneumophila urinary antigen test; Trinity Biotech, Bray, Ireland); (2) positive urinary antigen for Streptococcus pneumoniae (Binax Now $S$ pneumoniae urinary antigen test; Emergo Europe, The Netherlands); (2) positive bacterial culture from blood. The etiology was considered probable if one of the following criteria was met: (1) detection of RVs in throat swabs by RT-PCR using a Seeplex RV Detection Kit (Seegene Biotechnology Inc., Seoul, Korea) according to manufacturer's instructions, including respiratory syncytial virus (RSV) types $\mathrm{A}$ and $B$, influenza virus (IFV) types $A$ and $B$, parainfluenza virus (PIV) types $1,2,3$ and $4, \mathrm{HRV}$, enterovirus (EV), hCoV types 229E, NL63, OC43 and HKU1, hMPV, and adenovirus (AdV), bocavirus; (2) purulent sputum (defined as an adequate quality sputum sample with $>25$ leukocytes and $<10$ epithelial cells per $\times 100$ magnification field) with compatible findings of Gram staining; (3) detection of Mycoplasma pneumoniae (MP) in throat swabs by PCR as previously reported [15].

\section{Statistical analysis}

Categorical variables were described with counts and percentages. Data for continuous variables were presented as mean (SD) or median (IQR) where appropriate. The proportions of individuals in each age and PSI groups diagnosed with each pathogen of interest were compared using $X^{2}$ tests (SPSS for Windows 13.0).

\section{Results}

\section{Patient characteristics}

As seen in Figure 1, a total of 1013 adult CAP patients met the criteria were screened. Because of failing in sampling or follow-up, or confirmed with tuberculosis or non-pneumonia diseases (including lung cancer and etc.), 59 patients were excluded. Finally, etiological and clinical analysis was conducted on 954 patients (94.2\%), and $56.6 \%$ were males. The mean (SD) age was 45.2 (19.5) years (range 14-94), 184 (19.4\%) were aged $\geq 65$ years.

The main demographic and clinical characteristics of the study population are summarized in Table 1 . One hundred and eighty-four (19.3\%) patients had comorbidities record, such as coronary heart diseases (8.1\%), diabetes (7.6\%), chronic obstructive pulmonary disease (2.3\%) and etc. 254 (26.6\%) patients had smoking history. Within one year, $40(4.2 \%)$ and ten (1\%) patients had received influenza and streptococcus pneumonia vaccine. 


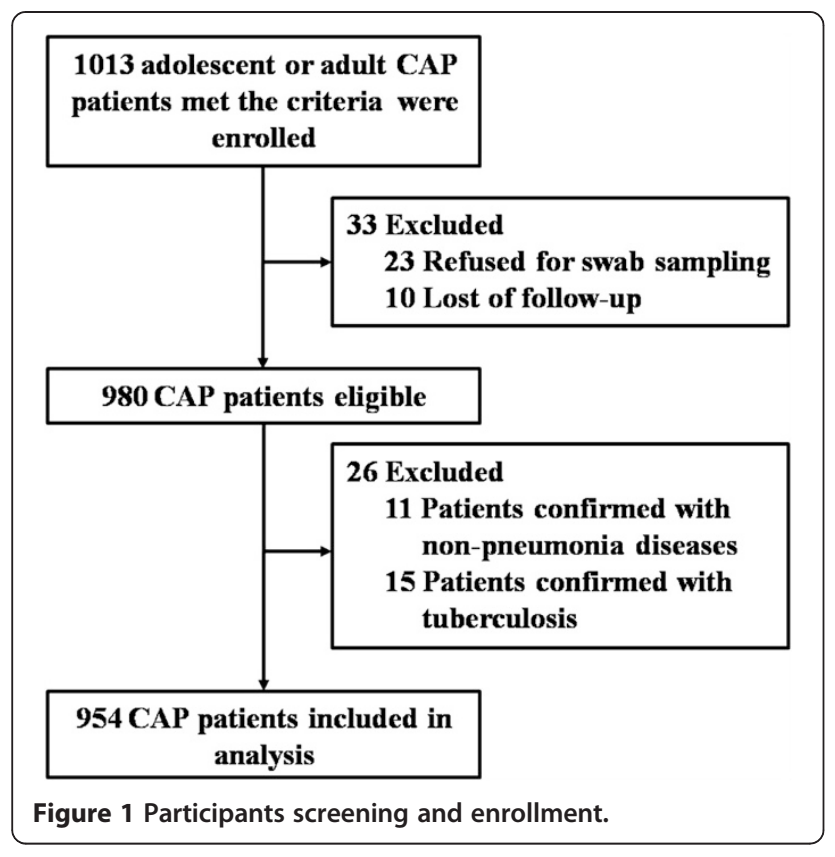

Six hundred and twenty-seven (65.7\%) patients were hospitalized, including six $(0.6 \%)$ in ICUs. Six hundred and twenty-five patients (65.5\%) had received antimicrobial treatment prior to enrollment. Common symptoms of the patients were fever (92\%), cough (91.7\%) and sputum production (70.4\%). After admission, 918 patients (96.2\%) and 26 patients $(2.7 \%)$ received antimicrobial and antiviral treatment. Median (IQR) score of PSI was 42 (36). Four patients (0.4\%) died within four weeks.

\section{Distribution of pathogens}

Etiological diagnoses were established in 393 patients (41.2\%), as shown in Table 2. The positive rate of RVs was $27.5 \%$. IFVA was dominant $(9.9 \%, 94 / 954)$. There were 60 cases of pH1N1, 30 cases of seasonal H3N2 (sH3N2) and four cases of both subtypes. Seven patients infected with $\mathrm{pH} 1 \mathrm{~N} 1$ had received influenza vaccine within one year. The detection rate of HRV was 4.3\%, and followed by AdV, 4.2\%; hMPV, 1.8\%; PIV1, 1.7\%; PIV3, 1.5\%; PIV2, 1.2\%; and IFVB, EV, RSVs, hCoV and PIV4 were rarely detected $(<1 \%)$. No bocavirus was detected.

The positive rate of bacteria was $23 \%$. Atypical bacterial pathogens, including Mycoplasma pneumoniae and Legionella pneumophila, were detected in 168 (17.6\%) and four $(0.4 \%)$ patients. Strectococcus pneumoniae was detected by urine antigen test in fifteen patients. In 533 CAP patients available with bacterial culture, typical bacterial pathogens were detected in 32 patients, mainly consisted of Klebsiella pneumoniae, Pseubomonas aeruginosa, Streptococcus pneumoniae and Haemophilus influenzae (data not shown).
Table 1 Epidemiological and clinical characteristics of study population

\begin{tabular}{|c|c|}
\hline Characteristics & n (\%) \\
\hline Total number of patients & 954 \\
\hline \multicolumn{2}{|l|}{ Demographic data } \\
\hline Age (years), mean $\pm S D$ & $45.2 \pm 19.5$ \\
\hline Gender male & $540(56.6)$ \\
\hline Comorbidities & $184(19.3)$ \\
\hline Coronary heart diseases & $77(8.1)$ \\
\hline Diabetes & $73(7.6)$ \\
\hline Chronic obstructive pulmonary disease & $22(2.3)$ \\
\hline Smoking (present or past) & $254(26.6)$ \\
\hline Influenza vaccine received within 1 year & $40(4.2)$ \\
\hline Streptococcus pneumonia vaccine received within 1 year & $10(1)$ \\
\hline \multicolumn{2}{|l|}{ Site of care } \\
\hline Outpatients & $327(34.3)$ \\
\hline Inpatients & $627(65.7)$ \\
\hline Ward & $621(65.1)$ \\
\hline ICU & $6(0.6)$ \\
\hline Antibiotics received before enrollment & $625(65.5)$ \\
\hline \multicolumn{2}{|l|}{ Symptoms } \\
\hline Fever & $878(92)$ \\
\hline $\mathrm{T}_{\max }\left({ }^{\circ} \mathrm{C}\right)$, mean $\pm \mathrm{SD}$ & $39.0 \pm 0.7$ \\
\hline Cough & $875(91.7)$ \\
\hline Sputum & $672(70.4)$ \\
\hline Shortness of breath & $137(14.4)$ \\
\hline Chest pain & $116(12.2)$ \\
\hline \multicolumn{2}{|l|}{ Laboratory findings } \\
\hline Procalcitonin ( $n=130$ ), median (IQR) & $0.17(0.42)$ \\
\hline C reactive protein $(n=671)$, median $(I Q R)$ & $42.5(86.8)$ \\
\hline WBC count $\left(\times 10^{9} / \mathrm{L}\right)$, median (IQR) & $7.6(4.7)$ \\
\hline $\mathrm{WBC}>10\left(\times 10^{9} / \mathrm{L}\right)$ & $257(26.9)$ \\
\hline WBC $<4\left(\times 10^{9} / L\right)$ & $61(6.4)$ \\
\hline \multicolumn{2}{|l|}{ Antimicrobial treatment after enrollment } \\
\hline Antibiotics & $918(96.2)$ \\
\hline Antivirals & $26(2.7)$ \\
\hline Length of hospital stay (days) & $9(6-14)$ \\
\hline PSI, median (IQR) & $42(36)$ \\
\hline Death & $4(0.4)$ \\
\hline
\end{tabular}

There were 257 patients with hyperleucocytosis, as shown in Table 1. Among these patients, 42 bacterial pathogens (including Mycoplasma pneumomniae, Streptococcus pneumoniae, Haemophilus influenzae and etc.) and 62 viral pathogens (including human rhinovirus, influenza virus $\mathrm{A}$, adenovirus and etc.) were detected. Mean (SD) score of PSI of hyperleucocytosis group was significantly 
Table 2 Etiology of study population with CAP

\begin{tabular}{ll}
\hline Pathogen identified & $\mathbf{n}(\%)$ \\
\hline At least one pathogen & $393(41.2)$ \\
Respiratory viruses (RVs) & $262(27.5)$ \\
Influenza virus A & $94(9.9)$ \\
$\quad$ Pandemic H1N1 (pH1N1) & $60(6.3)$ \\
$\quad$ Seasonal H3N2 (sH3N2) & $30(3.1)$ \\
pH1N1 and sH3N2 & $4(0.4)$ \\
Human rhinovirus & $41(4.3)$ \\
Adenovirus & $40(4.2)$ \\
Human metapneumovirus & $17(1.8)$ \\
Parainfluenza virus type 1 & $16(1.7)$ \\
Parainfluenza virus type 3 & $14(1.5)$ \\
Parainfluenza virus type 2 & $11(1.2)$ \\
Influenza virus B & $6(0.6)$ \\
Enterovirus & $5(0.5)$ \\
Respiratory syncytial virus type A & $5(0.5)$ \\
Respiratory syncytial virus type B & $4(0.4)$ \\
Human coronavirus types OC43/HKU1 & $4(0.4)$ \\
Human coronavirus types 229E/NL63 & $4(0.4)$ \\
Parainfluenza virus type 4 & $1(0.1)$ \\
Bocavirus & $0(0)$ \\
Bacteria & $219(23.0)$ \\
Mycoplasma pneumoniae & $168(17.6)$ \\
Typionella pneumophila & $4(0.4)$ \\
\hline & 47 \\
\hline
\end{tabular}

Data are expressed as $\mathrm{n}(\%)$.

higher than that of non-hyperleucocytosis group (53.75 \pm 25.03 v.s. $43.98 \pm 25.37, \mathrm{p}<0.001$ ).

Two or more causative agents were found in 75 patients (7.9\%), as shown in Table 3. The common associations among dual infections were: a RV and a bacterium in 48 cases (64\%), two RVs in 11 cases (14.7\%) and two bacteria in six cases (8\%). Triple, quadruple and quintuple infections were detected. IFV A, detected in 26 cases, was the most frequently RV in co-infections. PIVs were co-detected in 23 cases, HRVs in thirteen, AdVs in eight, hCoVs in five, RSVs and hMPVs in four, IFVs B in three, and $\mathrm{EV}$ in one.

Regarding on antiviral treatment, there were $16 \mathrm{pa}$ tients received oseltamivir among 94 IFV A infections. The clinical analysis of antiviral treatment revealed that the median length of hospitalization of antiviral group was significantly shorter than that of non-antiviral group ( 5.5 days v.s. 8 days, $\mathrm{p}=0.04$ ).

Two of the four dead patients were positive with pH1N1, the other two were positive with Streptococcus pneumoniae and Klebsiella pneumoniae, and Legionella pneumophila and human rhinovirus.
Table 3 Distribution of co-infections

\begin{tabular}{|c|c|}
\hline Associations & n (\%) \\
\hline Dual infections & $65(6.8)$ \\
\hline RV + Bacterium & 48 \\
\hline IFV A + Bacterium & 19 \\
\hline $\mathrm{HRV}+$ Bacterium & 9 \\
\hline PIVs + Bacterium & 8 \\
\hline$A d V+M P$ & 4 \\
\hline hCoVs + MP & 2 \\
\hline $\mathrm{IFV} B+\mathrm{MP}$ & 2 \\
\hline $\mathrm{RSV}$ s $+\mathrm{MP}$ & 2 \\
\hline hMPV + Bacterium & 2 \\
\hline$R V+R V$ & 11 \\
\hline $\mathrm{IFV} A+\mathrm{hCoVs}$ & 2 \\
\hline IFV A + PIVs & 2 \\
\hline$H R V+P I V s$ & 2 \\
\hline hMPV + PIVs & 2 \\
\hline$A d V+R S V A$ & 1 \\
\hline$A d V+P I V s$ & 1 \\
\hline$A d V+h C o V s$ & 1 \\
\hline Bacterium + Bacterium & 6 \\
\hline Triple infections & $8(0.84)$ \\
\hline IFV A (sH3N2) + PIV1 + PIV2 & 1 \\
\hline IFV A (sH3N2) + PIV2 + PIV3 & 1 \\
\hline IFV A (pH1N1) + two Bacteria & 1 \\
\hline HRV + PIV1 + PIV3 & 1 \\
\hline HRV + two bacteria & 1 \\
\hline PIV1 + EV + bacterium & 1 \\
\hline PIV1 + PIV3 + bacterium & 1 \\
\hline $\mathrm{IFV} B+\mathrm{AdV}+\mathrm{PIV} 3$ & 1 \\
\hline Quadruple infection & $1(0.1)$ \\
\hline PIV1 + PIV3 + two bacteria & 1 \\
\hline Quintuple infections & $1(0.1)$ \\
\hline $\mathrm{HRV}+\mathrm{PIV} 1+\mathrm{PIV} 2+\mathrm{PIV} 3+\mathrm{RSV} \mathrm{B}$ & 1 \\
\hline Total & $75 / 954(7.9)$ \\
\hline
\end{tabular}

Note: influenza virus (IFV) types $A$ and $B$, human rhinovirus (HRV), adenovirus (AdV), human metapneumovirus (hMPV), parainfluenza virus (PIV) types 1, 2, 3 and 4, enterovirus (EV), respiratory syncytial virus (RSV) types A and B, human coronaviruses (hCoVs), Mycoplasma pneumoniae (MP).

\section{Microbial etiology in age groups}

The study population was divided into four groups by age, $14 \sim 17$ years (adolescents), $18 \sim 44$ years (young adults), $45 \sim 64$ years (old adults) and $\geq 65$ years (elderly) as shown in Table 4, to look for pathogens more commonly associated with an age group. The microbial etiology was determined in $70 \%, 44.5 \%, 37.9 \%$ and $30.3 \%$ for four groups respectively ( $\mathrm{p}<0.001$ ), and co-infection rate decreased (14\%, $9 \%, 5.9 \%$ and $6.3 \%$ respectively). 
Table 4 Etiology of CAP according to age

\begin{tabular}{|c|c|c|c|c|c|}
\hline Etiology & $14 \sim 17$ yrs $(n=50)$ & $18 \sim 44$ yrs $(n=443)$ & $45 \sim 64$ yrs $(n=272)$ & $65 \sim 94$ yrs $(n=189)$ & $\mathrm{p}$ value \\
\hline At least one pathogen & $35(70)$ & $197(44.5)$ & $103(37.9)$ & $58(30.3)$ & $<0.001$ \\
\hline Respiratory viruses (RV) & $15(30)$ & $104(23.5)$ & $72(26.5)$ & $45(23.8)$ & 0.651 \\
\hline $\mathrm{IFV}^{\mathrm{d}}$ & $2(4)$ & $32(7.2)$ & $38(14)$ & $22(11.6)$ & $<0.001$ \\
\hline $\mathrm{pH} 1 \mathrm{~N} 1$ & $2(4)$ & $20(4.5)$ & $24(8.8)$ & $14(7.4)$ & 0.743 \\
\hline sH3N2 & 0 & $9(2)$ & $14(5.1)$ & $7(3.7)$ & \\
\hline $\mathrm{pH} 1 \mathrm{~N} 1$ and $\mathrm{sH} 3 \mathrm{~N} 2$ & 0 & $3(0.7)$ & 0 & $1(0.5)$ & \\
\hline HRV & $2(4)$ & $19(4.3)$ & $13(4.8)$ & $7(3.7)$ & 0.962 \\
\hline$A d V^{a b c d}$ & $7(14)$ & $23(5.2)$ & $5(1.8)$ & $5(2.6)$ & $<0.001$ \\
\hline HMPV & 0 & $6(1.4)$ & $6(2.2)$ & $5(2.6)$ & 0.524 \\
\hline PIV 1 & $2(4)$ & $8(1.8)$ & $2(0.7)$ & $4(2.1)$ & 0.236 \\
\hline PIV 3 & $2(4)$ & $7(1.6)$ & $3(1.1)$ & $2(1.1)$ & 0.384 \\
\hline PIV 2 & $1(2)$ & $9(2)$ & $1(0.4)$ & 0 & 0.053 \\
\hline IFV B & $1(2)$ & $3(0.7)$ & $1(0.4)$ & $1(0.5)$ & 0.495 \\
\hline EV & $1(2)$ & $3(0.7)$ & $1(0.4)$ & 0 & 0.301 \\
\hline RSVA & 0 & $4(0.9)$ & $1(0.4)$ & 0 & 0.628 \\
\hline RSV B & 0 & $4(0.9)$ & 0 & 0 & 0.351 \\
\hline HCoV OC43/HKU1 & 0 & $2(0.5)$ & $2(0.7)$ & 0 & 0.739 \\
\hline HCoV 229E/NL63 & 0 & $3(0.7)$ & $1(0.4)$ & 0 & 0.853 \\
\hline PIV 4 & 0 & $1(0.2)$ & 0 & 0 & 1.000 \\
\hline Bacteria & $26(52)$ & $120(27.1)$ & $44(16.2)$ & $27(14.3)$ & \\
\hline MPabcde & $25(50)$ & $106(23.9)$ & $24(8.8)$ & $13(6.9)$ & $<0.001$ \\
\hline LP & $1(2)$ & $2(0.5)$ & $1(0.4)$ & 0 & 0.262 \\
\hline Typical bacteriacde & 0 & $12(2.7)$ & $19(7)$ & $14(7.4)$ & 0.005 \\
\hline Two or more pathogens & $7(14)$ & $40(9)$ & $16(5.9)$ & $12(6.3)$ & 0.141 \\
\hline
\end{tabular}

Data are expressed as $\mathrm{n}(\%)$.

${ }^{a}: \mathrm{p}<0.05,14 \sim 17$ yrs group vs $18 \sim 44$ yrs group;

b: $\mathrm{p}<0.05,14 \sim 17$ yrs group vs $45 \sim 64$ yrs group;

c: $\mathrm{p}<0.05,14 \sim 17$ yrs group vs $65 \sim 94$ yrs group;

d: $p<0.05,18 \sim 44$ yrs group vs $45 \sim 64$ yrs group;

e. $p<0.05,18 \sim 44$ yrs group vs $65 \sim 94$ yrs group;

Note: influenza virus (IFV) types A and B, human rhinovirus (HRV), adenovirus (AdV), human metapneumovirus (hMPV), parainfluenza virus (PIV) types 1, 2, 3 and 4, enterovirus (EV), respiratory syncytial virus (RSV) types A and B, human coronavirus (hCoV) types 229E, NL63, OC43 and HKU1, Mycoplasma pneumoniae (MP) and Legionella pneumophila (LP).

IFV A was more frequently found in old adults and elderly groups $(\mathrm{p}<0.001)$. HRV was equally detected in all age groups. The frequency of AdV decreased according to the four groups $(\mathrm{p}<0.001)$, and similar trend was found in PIV $2(\mathrm{p}=0.053)$ and MP $(\mathrm{p}<0.001)$. No hMPV was detected in adolescents, and no RSV or $\mathrm{hCoV}$ was found in adolescents and elderly adults. The frequencies of typical bacterial pathogens increased according to age group $(\mathrm{p}=0.005)$.

\section{Microbial etiology according to severity score}

To explore the association between pathogens and the severity score, patients were also separated into three groups according to severity score (PSI), as indicated in Table 5. In three groups, though pathogens detection rates were different, RVs ranked first $(25.1 \%, 19.5 \%$ and
$30.4 \%$, respectively). All RVs were detected in low risk group. The frequency of IFV A increased along with severity (from $9.4 \%$ and $8.8 \%$ to $17.9 \%$ ). Significant difference ( $p=0.018)$ was found in subtypes of IFV A among PSI groups, especially for $\mathrm{pH} 1 \mathrm{~N} 1(\mathrm{p}<0.05)$. Similar trend was found in the distribution of typical bacterial pathogens $(p=0.001)$. The distributions of HRV, AdV and hMPV in three groups were comparable. The frequency of MP decreased in moderate- and high-risk groups, whereas that of the mixed etiology decreased first (5.3\%), then increased (8.9\%).

\section{Discussion}

To our knowledge, this is the largest scale investigation of common RV infections in China in adolescents and adults with CAP, using PCR-based method. The CAP 
Table 5 Etiology of CAP according to PSI

\begin{tabular}{|c|c|c|c|c|}
\hline & PSI I-II (n = 785) & PSI III $(n=113)$ & PSI IV-V $(n=56)$ & $p$ value \\
\hline At least one pathogen & $333(42.5)$ & $35(29)$ & $25(44.6)$ & 0.219 \\
\hline Respiratory viruses (RV) & $197(25.1)$ & $22(19.5)$ & $17(30.4)$ & 0.267 \\
\hline IFV A & $74(9.4)$ & $10(8.8)$ & $10(17.9)$ & 0.118 \\
\hline $\mathrm{pH} 1 \mathrm{~N} 1^{\mathrm{bc}}$ & $42(5.4)$ & $8(7.1)$ & $10(17.9)$ & 0.018 \\
\hline sH3N2 & $28(3.6)$ & $2(1.8)$ & 0 & \\
\hline $\mathrm{pH} 1 \mathrm{~N} 1$ and $\mathrm{sH} 3 \mathrm{~N} 2$ & $4(0.5)$ & 0 & 0 & \\
\hline HRV & $33(4.2)$ & $5(4.4)$ & $3(5.4)$ & 0.854 \\
\hline AdV & $36(4.6)$ & $3(2.7)$ & $1(1.8)$ & 0.542 \\
\hline HMPV & $14(1.8)$ & $1(0.9)$ & $2(3.6)$ & 0.391 \\
\hline PIV 1 & $15(1.9)$ & $1(0.9)$ & 0 & 0.668 \\
\hline PIV 3 & $13(1.7)$ & 0 & $1(1.8)$ & 0.445 \\
\hline PIV 2 & $10(1.3)$ & $1(0.9)$ & 0 & 1.000 \\
\hline IFV B & $6(0.8)$ & 0 & 0 & 1.000 \\
\hline EV & $4(0.5)$ & $1(0.9)$ & 0 & 0.624 \\
\hline RSVA & $4(0.5)$ & $1(0.9)$ & 0 & 0.624 \\
\hline RSV B & $4(0.5)$ & 0 & 0 & 1.000 \\
\hline HCoV OC43/HKU1 & $4(0.5)$ & 0 & 0 & 1.000 \\
\hline HCoV 229E/NL63 & $4(0.5)$ & 0 & 0 & 1.000 \\
\hline PIV 4 & $1(0.1)$ & 0 & 0 & 1.000 \\
\hline Bacteria & $187(23.9)$ & $17(15.1)$ & $13(23.2)$ & \\
\hline$M P^{a}$ & $157(20)$ & $6(5.3)$ & $5(8.9)$ & $<0.001$ \\
\hline LP & $2(0.3)$ & $2(1.8)$ & 0 & 0.146 \\
\hline Typical bacteria ${ }^{\mathrm{ab}}$ & $28(3.6)$ & $9(8)$ & $8(14.3)$ & 0.001 \\
\hline Two or more pathogens & $64(8.2)$ & $6(5.3)$ & $5(8.9)$ & 0.562 \\
\hline
\end{tabular}

Data are expressed as $\mathrm{n}(\%)$.

a: $p<0.05$, PSI I-II vs III;

b: $p<0.05$, PSI I-II vs IV-V;

c: $p<0.05$, PSI III vs IV-V;

Note: influenza virus (IFV) types $A$ and B, human rhinovirus (HRV), adenovirus (AdV), human metapneumovirus (hMPV), parainfluenza virus (PIV) types 1, 2, 3 and 4, enterovirus (EV), respiratory syncytial virus (RSV) types A and B, human coronavirus (hCoV) types 229E, NL63, OC43 and HKU1, Mycoplasma pneumoniae (MP) and Legionella pneumophila (LP).

patients in our group were different from other CAP studies with specific feathers as below, (1) young, mean (SD) age was 45.24 (19.478) years; (2) $82.3 \%$ of the patients' PSI classes wereI-III; (3) low numbers of ICU admission and deaths; (4) 9 of 12 teaching hospitals functioned as primary care facilities. Our results indicated that $27.5 \%$ of CAP patients have evidence of viral infection. It has been generally assumed that for respiratory infections due to viruses, the optimal specimen is the nasopharyngeal aspirate, rather than throat swabs we used here [16]. Actually, the detection rate was higher than $22 \%$ reported by Ruuskanen O et al. [6] based on 2910 CAP patients from 10 studies, also higher than 5-20\% reported by other studies that had not used PCRbased assays [17].

IFV A was the first ranking viral pathogen. Among 94 cases, 68 (72.3\%) had IFV A as the only identified pathogen, $20(21.3 \%)$ had co-infection with bacteria, and six
(6.4\%) had co-infection with other RVs. Similar with other reports $[18,19]$, the analysis of subtypes of IFV A revealed that $\mathrm{pH} 1 \mathrm{~N} 1$ virus was circulating along with sH3N2 virus, as this surveillance was carried out from the post-pandemic period of pH1N1 [20]. It has been reported that younger age and more severe respiratory compromise are key features of patients with pH1N1associated pneumonia compared with seasonal influenza pneumonia [21]. Here, oppositely, pH1N1 infected patients were mostly distributed in patients older than 45 years, which was coincident with the findings reported by Viasus $\mathrm{D}$ et al. [22]. This upward shift in age distribution is probably due to a higher seropositivity against A (H1N1) pdm09 virus in young adult patients. On the other side, although IFV A infected cases distributed through all PSI groups, all cases in high risk group were determined as pH1N1 (accounting for 16.7\%, p < 0.05). And $93.3 \%$ of sH3N2 positive patients were found in low 
risk group, without high-risk cases. Two of four dead patients were caused by pH1N1. These findings suggest that the severity of $\mathrm{pH} 1 \mathrm{~N} 1$-associated CAP is still higher [22]. Four co-infection cases of pH1N1 and H3N2 were presented with PSI I-II, the reason was unclear. Further analysis of corresponding viral load and antiviral treatment might be needed.

In agreement with our results (HRV, 4.3\%), two recently reports using PCR assays suggested that HRV was important cause in CAP, with infection rates of 4.9\% [23] and 7\% [24]. Among 41 infections, 27 patients $(65.9 \%)$ had HRV as the only identified pathogen, ten $(24.4 \%)$ had co-infection with bacteria, and four (9.7\%) had co-infection with other RVs. These results stand in contrast to those of previous studies, which reported that HRV commonly occurred with bacterial coinfection (approximately 41.9-57.1\%) [25,26]. Moreover, it is reported that HRV single or mixed HRV / pneumococcal infection should be an independent cause of severe pneumonia [25-27]. In our study, oppositely, HRV infections occurred in all age and severity groups.

The incidence of adenovirus was $4.2 \%$, which was in the upper scale of the range of $<1 \%-4 \%$ as reported [12]. Although most infected cases are self-limited, adenovirus is recognized as one of the first viruses clearly linked with pneumonia [12]. David Lieberman's team had found that $1.6 \%$ of adults CAP patients caused by adenovirus, and no such cases had been detected in healthy controls or non-pneumonia low respiratory tract infection cohort [23]. Few studies reported on the coinfection of adenovirus with other pathogens, here, we found four with MP and four with other RVs, accounting for $20 \%$. Lauderdalea et al. reported that all infections of AdV were found in 17-44 years-old patients [28]. Similarly, the incidence was significantly higher in adolescents and younger adults $(\mathrm{p}<0.001)$.

Regarding on other important viruses, the frequencies of PIVs, RSV, hMPV and HCoVs were lower than that of Dr. Andrew T. Pavia's report [12]. Since most respiratory viruses are highly seasonal, the frequencies might be influenced by the variation in intensity of the study period, age of the population and region.

In this surveillance, CAP patients due to MP, an important atypical bacterial pathogen, were common in $14 \sim 44$ years-old patients and recognized by PSI as a low-risk condition, which is in consistent with the previous findings $[29,30]$. Just as Roson et al. reported, the patients with bacterial infections were usually associated with increased severity and mortality [31]. The analysis of typical bacterial pathogens indicated that the incidence increased along with age and PSI classes of the patients. And one patient died from co-infection of Streptococcus pneumoniae and Klebsiella pneumoniae. However, bacterial pneumonia might be underdiagnosed in this study [1,32] due to the reasons: (1) we focused on viral pathogens, therefore patients unavailable with a blood or sputum culture were not excluded. Only 533 patients were detected for typical bacterial pathogens, though urinary antigen test was conducted in all patients; (2) the defined population was young and had low or moderate severity; (3) the rate of antimicrobial treatment before enrollment was high (65.5\%).

Our study is subject to two limitations. First, as reported by David Lieberman [23], RVs could be detected in $7.1 \%$ of 450 controls without respiratory complaints. Healthy controls were not included to clarify the clinical significance of RVs, especially for the cases of triple and quadruple infections. Second, clinical relevance of viral load in the specimens could not be analyzed since the study was carried out in qualitative assays.

\section{Conclusions}

The proportion of RV involvement in CAP is higher than previously reported. Influenza virus A pneumonia are usually found in patients older than 45 years, while, adenovirus pneumonia are commonly found in adolescents and young adult patients. Pandemic H1N1 virus is still recognized by PSI as a high-severity pathogen. The findings contribute baseline data on viral CAP study in China.

\section{Abbreviations}

CAP: Community-acquired pneumonia; RV: Respiratory virus; PSI: Pneumonia severity index; SARS: Severe acute respiratory syndrome; IFV: Influenza virus; HRV: Human rhinovirus; AdV: Adenovirus; hMPV: Human metapneumovirus; PIV: Parainfluenza virus; EV: Enterovirus; RSV: Respiratory syncytial virus; hCoV: Human coronavirus; MP: Mycoplasma pneumoniae.

\section{Competing interests}

The authors declare that they have no competing interest.

\section{Authors' contributions}

QJX carried out all laboratory tests, performed the statistical analysis, participated in the design and coordination of the study and drafted the manuscript. GL, PZH, YXM, LYM, LR and WYM participated in enrollment of CAP patients and recorded the demographic information. CB and WC participated in the design and coordination of the study, and helped to draft the manuscript. All authors read and approved the final manuscript.

\section{Acknowledgement}

We thank Drs. Jian-Ping Dong, Feng Gao, Yan Gao, Ming Hu and Yong-Xiang Zhang from BNACAP, for their help with the collection of specimens and clinical data. We also specially acknowledge the modification of manuscript by Miss Shu-Yan Chen.

\section{Funding}

This work was supported by China National Funds for Distinguished Young Scientists (H0104/81425001), the Beijing Science and Technology Project [grant numbers D101100049810002, Z131100002613001], the National Major S\&T Research Projects for the Control and Prevention of Major Infectious Diseases in China [grant number 2012ZX10004-206], New Century Excellent Talents in University [grant number NCET-09-0006], Beijing Municipal Health Bureau grant [grant number 2011-1004-02], and the National Natural Science Foundation of China [grant numbers 81070005/H0104, 81030032/H19 and 81271840] 


\section{Author details}

'Department of Infectious diseases and Clinical Microbiology, Beijing Chao-Yang Hospital, Capital Medical University, Beijing Institute of Respiratory Medicine, No 8 Gongti Nanlu, ChaoYang District, Beijing 100020, China. ${ }^{2}$ Department of Infectious diseases, YanTai Yu Huang-Ding Hospital, Yantai, China. ${ }^{3}$ Department of Respiratory Medicine, Capital Medical University; Beijing Institute of Respiratory Medicine; Beijing Key Laboratory of Respiratory and Pulmonary Circulation Disorders, Beijing, China.

\section{Received: 26 February 2014 Accepted: 6 February 2015}

\section{Published online: 22 February 2015}

\section{References}

1. Welte T, Torres A, Nathwani D. Clinical and economic burden of community-acquired pneumonia among adults in europe. Thorax. 2012;67:71-9.

2. Mandell LA, Bartlett JG, Dowell SF, File Jr TM, Musher DM, Whitney C. Update of practice guidelines for the management of community-acquired pneumonia in immunocompetent adults. Clin Infect Dis. 2003;37:1405-33.

3. Mandell LA, Wunderink RG, Anzueto A, Bartlett JG, Campbell GD, Dean NC, et al. Infectious diseases society of america/american thoracic society consensus guidelines on the management of community-acquired pneumonia in adults. Clin Infect Dis. 2007;44 Suppl 2:S27-72.

4. Esposito S, Daleno C, Prunotto G, Scala A, Tagliabue C, Borzani I, et al. Impact of viral infections in children with community-acquired pneumonia: results of a study of 17 respiratory viruses. Influenza Other Respi Viruses. 2013;7:18-26.

5. Bezerra PG, Britto MC, Correia JB, Duarte MC, Fonceca AM, Rose K, et al. Viral and atypical bacterial detection in acute respiratory infection in children under five years. PLoS One. 2011;6:e18928.

6. Ruuskanen O, Lahti E, Jennings LC, Murdoch DR. Viral pneumonia. Lancet. 2011;377:1264-75.

7. Fouchier RA, Rimmelzwaan GF, Kuiken T, Osterhaus AD. Newer respiratory virus infections: human metapneumovirus, avian influenza virus, and human coronaviruses. Curr Opin Infect Dis. 2005;18:141-6.

8. Larcher C, Jeller V, Fischer H, Huemer HP. Prevalence of respiratory viruses, including newly identified viruses, in hospitalised children in austria. Eur J Clin Microbiol Infect Dis. 2006;25:681-6.

9. Tiveljung-Lindell A, Rotzen-Ostlund M, Gupta S, Ullstrand R, Grillner L, Zweygberg-Wirgart B, et al. Development and implementation of a molecular diagnostic platform for daily rapid detection of 15 respiratory viruses. J Med Virol. 2009;81:167-75.

10. Arens MQ, Buller RS, Rankin A, Mason S, Whetsell A, Agapov E, et al. Comparison of the eragen multi-code respiratory virus panel with conventional viral testing and real-time multiplex pcr assays for detection of respiratory viruses. J Clin Microbiol. 2010;48:2387-95.

11. Do AH, van Doorn HR, Nghiem MN, Bryant JE, Hoang TH, Do QH, et al. Viral etiologies of acute respiratory infections among hospitalized vietnamese children in ho chi minh city, 2004-2008. PLoS One. 2011;6:e18176.

12. Pavia AT. What is the role of respiratory viruses in community-acquired pneumonia?: what is the best therapy for influenza and other viral causes of community-acquired pneumonia? Infect Dis Clin North Am. 2013;27:157-75.

13. Qu J, Gu L, Wu J, Dong J, Pu Z, Gao Y, et al. Accuracy of igm antibody testing, fq-pcr and culture in laboratory diagnosis of acute infection by mycoplasma pneumoniae in adults and adolescents with communityacquired pneumonia. BMC Infect Dis. 2013;13:172.

14. Fine MJ, Auble TE, Yealy DM, Hanusa BH, Weissfeld LA, Singer DE, et al. A prediction rule to identify low-risk patients with community-acquired pneumonia. N Engl J Med. 1997;336:243-50.

15. Waites KB, Nolte FS. Laboratory diagnosis of mycoplasmal infections. Washington, D.C.: ASM Press; 2001.

16. Loens K, Van Heirstraeten L, Malhotra-Kumar S, Goossens H, leven M. Optimal sampling sites and methods for detection of pathogens possibly causing community-acquired lower respiratory tract infections. J Clin Microbiol. 2009;47:21-31.

17. File TM. Community-acquired pneumonia. Lancet. 2003;362:1991-2001.

18. Win MK, Chen MI, Barkham T, Lin C, Tan A, Lin R, et al. Influenza disease burden in adults by subtypes following the initial epidemic of pandemic h1n1 in singapore. Influenza Other Respi Viruses. 2011;5:e563-7.
19. Chuang JH, Huang AS, Huang WT, Liu MT, Chou JH, Chang FY, et al. Nationwide surveillance of influenza during the pandemic (2009-10) and post-pandemic (2010-11) periods in taiwan. PLoS One. 2012;7:e36120.

20. Eurosurveillance Editorial Team. World health organization declares postpandemic phase. Euro Surveill. 2010;15(32):pii=19636.

21. Riquelme R, Torres A, Rioseco ML, Ewig S, Cillóniz C, Riquelme M, et al. Influenza pneumonia: a comparison between seasonal influenza virus and the h1n1 pandemic. Eur Respir J. 2011;38:106-11.

22. Viasus D, Cordero E, Rodriguez-Bano J, Oteo JA, Fernández-Navarro A, Ortega $L$, et al. Changes in epidemiology, clinical features and severity of influenza a (h1n1) 2009 pneumonia in the first post-pandemic influenza season. Clin Microbiol Infect. 2012;18:E55-62.

23. Lieberman D, Shimoni A, Shemer-Avni Y, Keren-Naos A, Shtainberg R. Respiratory viruses in adults with community-acquired pneumonia. Chest. 2010;138:811-6.

24. Johansson N, Kalin M, Tiveljung-Lindell A, Giske CG, Hedlund J. Etiology of community-acquired pneumonia: Increased microbiological yield with new diagnostic methods. Clin Infect Dis. 2010;50:202-9.

25. Hohenthal U, Vainionpaa R, Nikoskelainen J, Kotilainen P. The role of rhinoviruses and enteroviruses in community acquired pneumonia in adults. Thorax. 2008;63:658-9.

26. Jennings LC, Anderson TP, Beynon KA, Chua A, Laing RT, Werno AM, et al. Incidence and characteristics of viral community-acquired pneumonia in adults. Thorax. 2008;63:42-8.

27. Choi SH, Hong SB, Ko GB, Lee Y, Park HJ, Park SY, et al. Viral infection in patients with severe pneumonia requiring intensive care unit admission. Am J Respir Crit Care Med. 2012;186:325-32.

28. Lauderdale TL, Chang FY, Ben RJ, Yina HC, Nib YH, Tsai JW, et al. Etiology of community acquired pneumonia among adult patients requiring hospitalization in taiwan. Respir Med. 2005;99:1079-86.

29. Cao B, Ren LL, Zhao F, Gonzalez R, Song SF, Bai L, et al. Viral and mycoplasma pneumoniae community-acquired pneumonia and novel clinical outcome evaluation in ambulatory adult patients in china. Eur J Clin Microbiol Infect Dis. 2010;29:1443-8.

30. Hohenthal U, Vainionpaa R, Meurman O, Vahtera A, Katiskalahti T, Nikoskelainen J, et al. Aetiological diagnosis of community acquired pneumonia: Utility of rapid microbiological methods with respect to disease severity. Scand J Infect Dis. 2008;40:131-8.

31. Roson B, Carratala J, Dorca J, Casanova A, Manresa F, Gudiol F. Etiology, reasons for hospitalization, risk classes, and outcomes of communityacquired pneumonia in patients hospitalized on the basis of conventional admission criteria. Clin Infect Dis. 2001;33:158-65.

32. van der Poll T, Opal SM. Pathogenesis, treatment, and prevention of pneumococcal pneumonia. Lancet. 2009;374:1543-56.

\section{Submit your next manuscript to BioMed Central and take full advantage of:}

- Convenient online submission

- Thorough peer review

- No space constraints or color figure charges

- Immediate publication on acceptance

- Inclusion in PubMed, CAS, Scopus and Google Scholar

- Research which is freely available for redistribution 